\title{
Country of first birth and neonatal outcomes in migrant and Norwegian-born parous women in Norway: a population- based study
}

Eline S. Vik ${ }^{1,2^{*}}$ (D, Roy M. Nilsen ${ }^{1}$, Vigdis Aasheim ${ }^{1}$, Rhonda Small ${ }^{3,4}$, Dag Moster ${ }^{2,5}$ and Erica Schytt ${ }^{1,3,6}$

\begin{abstract}
Background: This study compares subsequent birth outcomes in migrant women who had already had a child before arriving in Norway with those in migrant women whose first birth occurred in Norway. The aim of this study was to investigate the associations between country of first birth and adverse neonatal outcomes (very preterm birth, moderately preterm birth, post-term birth, small for gestational age, large for gestational age, low Apgar score, stillbirth and neonatal death) in parous migrant and Norwegian-born women.

Methods: National population-based study including second and subsequent singleton births in Norway from 1990 to 2016. Data were retrieved from the Medical Birth Registry of Norway and Statistics Norway. Neonatal outcomes were compared between births to: 1) migrant women with a first birth before immigration to Norway $(n=30,062)$ versus those with a first birth after immigration $(n=66,006)$, and 2) Norwegian-born women with a first birth outside Norway $(n=6205)$ versus those with a first birth in Norway $(n=514,799)$. Associations were estimated as crude and adjusted odds ratios (aORs) with 95\% confidence intervals (Cls) using multiple logistic regression.

Results: Migrant women with a first birth before immigrating to Norway had increased odds of adverse outcomes in subsequent births relative to those with a first birth after immigration: very preterm birth (22-31 gestational weeks; $\mathrm{aOR}=1.27 ; \mathrm{Cl} 1.09-1.48)$, moderately preterm birth (32-36 gestational weeks; $\mathrm{aOR}=1.10 ; \mathrm{Cl} 1.02-1.18$ ), post-term birth ( $\geq 42$ gestational weeks; $\mathrm{aOR}=1.19 ; \mathrm{Cl} 1.11-1.27)$, low Apgar score $(<7$ at $5 \mathrm{~min} ; \mathrm{aOR}=1.27 ; \mathrm{Cl} 1.16-1.39)$ and stillbirth $(\mathrm{aOR}=1.29 ; \mathrm{Cl} 1.05-1.58)$. Similar results were found in the sample of births to Norwegian-born women.

Conclusions: The increased odds of adverse neonatal outcomes for migrant and Norwegian-born women who had their first births outside Norway should serve as a reminder of the importance of taking a careful obstetric history in these parous women to ensure appropriate care for their subsequent pregnancies and births in Norway.
\end{abstract}

Keywords: Immigration, Parous women, Neonatal outcomes, Obstetric history, Predictor

\footnotetext{
* Correspondence: eline.skirnisdottir.vik@hvl.no

${ }^{1}$ Faculty of Health and Social Sciences, Western Norway University of Applied Sciences, Campus Kronstad, Inndalsveien 28, 5063 Bergen, Norway

${ }^{2}$ Department of Global Public Health and Primary Care, University of Bergen, Bergen, Norway

Full list of author information is available at the end of the article
}

(c) The Author(s). 2020 Open Access This article is licensed under a Creative Commons Attribution 4.0 International License, which permits use, sharing, adaptation, distribution and reproduction in any medium or format, as long as you give appropriate credit to the original author(s) and the source, provide a link to the Creative Commons licence, and indicate if changes were made. The images or other third party material in this article are included in the article's Creative Commons licence, unless indicated otherwise in a credit line to the material. If material is not included in the article's Creative Commons licence and your intended use is not permitted by statutory regulation or exceeds the permitted use, you will need to obtain permission directly from the copyright holder. To view a copy of this licence, visit http://creativecommons.org/licenses/by/4.0/ The Creative Commons Public Domain Dedication waiver (http://creativecommons.org/publicdomain/zero/1.0/) applies to the data made available in this article, unless otherwise stated in a credit line to the data. 


\section{Background}

The World Health Organization promotes reducing health inequalities for migrant families [1]. With the growing proportion of migrant women giving birth in high-income countries [1, 2], increased knowledge about their pregnancy outcomes is needed [3]. Migrant women may be of good health, sometimes even better health than the host population; a phenomenon often referred to as the healthy migrant effect $[4,5]$. However, increased risk of adverse pregnancy outcomes including preterm birth $[6,7]$ and perinatal mortality [8] have been reported for refugees in particular.

Nearly half of women giving birth in high income countries are parous [9] and maternity care is mainly tailored to the host population with particular focus on first-time mothers and those with a complicated first pregnancy and childbirth [10]. We have previously reported that migrant women who gave birth to their first baby before immigration to Norway had an increased risk of stillbirth in later births compared with migrant women who gave birth to their first baby in Norway [11]. In the current study, we explore whether this increased risk applies also to other adverse neonatal outcomes, and whether the findings are unique to migrant women or if they also apply to Norwegian-born women who return to Norway after a first childbirth abroad.

The aim was to investigate the associations between country of first birth and adverse neonatal outcomes (very preterm birth, moderately preterm birth, post-term birth, small for gestational age, large for gestational age, low Apgar score, stillbirth and neonatal death) in parous migrant and Norwegian-born women in Norway.

\section{Methods}

\section{Study design}

In this national population-based study, we used individual record data from the Medical Birth Registry of Norway (MBRN) $[12,13]$ and Statistics Norway (SSB) [14]. The data were merged using each woman's unique national identity number. The MBRN is the repository for mandatory notification of all births in Norway, and includes information on women's obstetric background, maternal health before and during pregnancy, current pregnancy, labour and birth, and maternal and infant outcomes. The MBRN data are collected from medical records and women's self-reported obstetric history. SSB provides information on migration and socioeconomic factors.

\section{Setting}

In Norway, the health care system is considered of high quality with low maternal and child mortality rates [15]. All women are entitled to free maternity care in Norway, and the vast majority of women give birth in public hospitals (99\%) [16]. Unless there are medical complications necessitating specialist obstetric care, women may choose antenatal care provided by either a general practitioner, a midwife, or a combination of the two [17]. However, inequalities in health care have been reported and migrant women in Norway appear more likely to receive suboptimal care compared to non-migrant women [18]. In 2018, $29 \%$ of children born in Norway were born to a migrant mother [19].

\section{Study population}

The main goal of this study was to compare subsequent birth outcomes in migrant women who already had a child before arriving in Norway (defined as the exposure group) with the same outcomes in migrant women with a first birth in Norway (defined as the comparison group). In order to control for possible parity-related differences between exposure and comparison groups, we restricted the exposure group to include women with only one birth before arriving in Norway (Fig. 1).

Initially, MBRN comprised 1,620,532 births during the period 1990-2016. Births to second generation migrant women, those with unknown or mixed background, such as adoptees or women with one Norwegian-born and one foreign-born parent, were excluded $(n=87,696)$. The final sample included the second and any subsequent singleton births to foreign-born women with two foreign-born parents ( $n=96,068$ births to migrant women), and Norwegianborn women with two Norwegian-born parents $(n=521$, 004 births to Norwegian-born women) giving birth in Norway between the years 1990 and 2016 (Fig. 1).

\section{Country of woman's first birth}

To derive information on whether a woman had a first child before or after immigration to Norway, we used the following algorithms:

\section{Migrant women}

The country of a woman's first birth was determined by the woman's first parity registered in the MBRN dataset. If a parous woman's first birth was in the dataset, the birthplace of her firstborn baby was classified as Norway. If the woman's first birth was not in the dataset, the birthplace was classified as other than Norway. Women with permission to stay in Norway prior to 1990 may or may not have given birth in Norway before 1990 (the study period commencement) and were therefore excluded $(n=35,929)$.

\section{Norwegian-born women}

To identify country of first birth we excluded births to any woman 13 years or older in 1990 whose first birth was not available in the MBRN dataset $(n=193,243)$ and therefore could in theory have had previous babies 


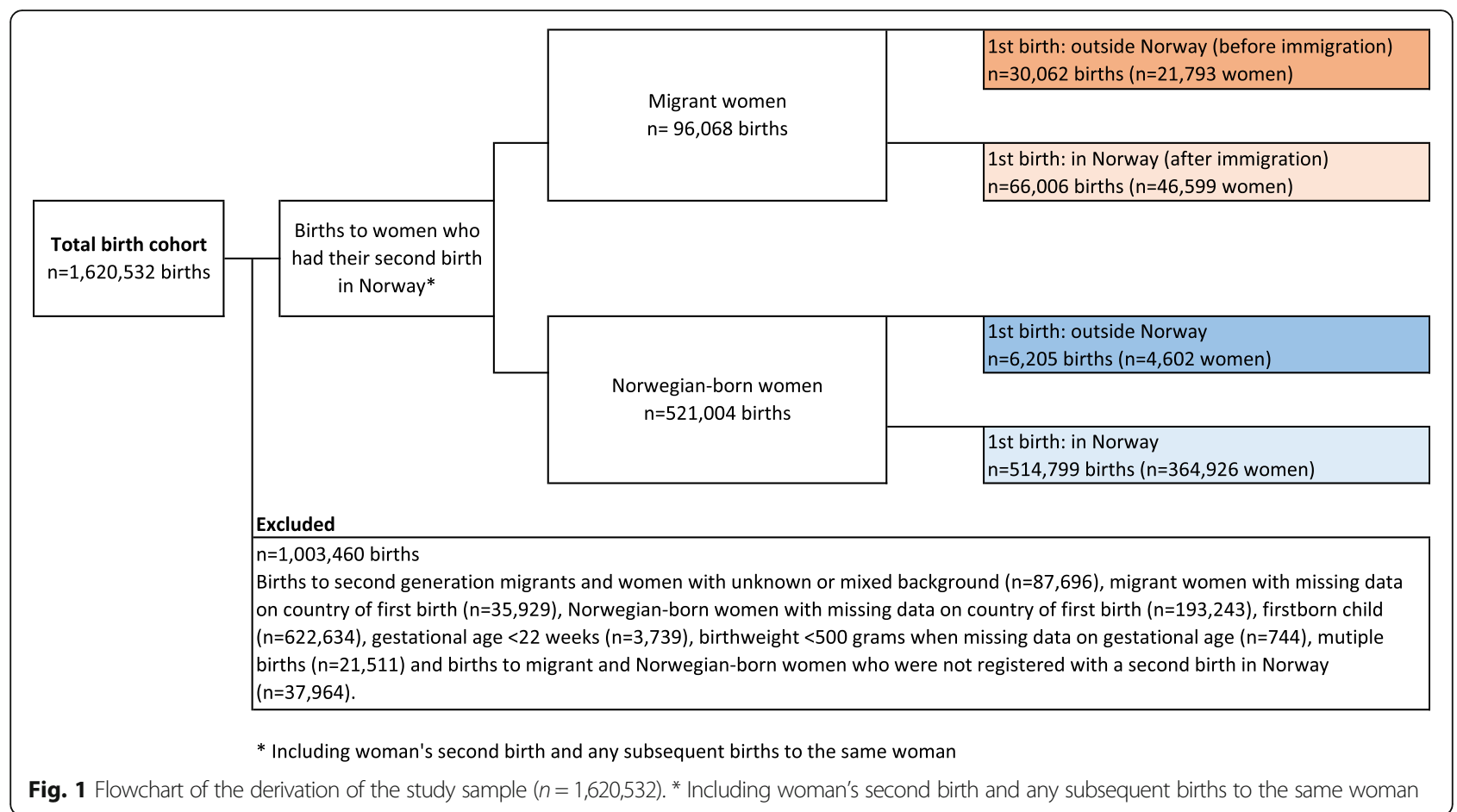

before 1990. The women's first parity registered in the dataset was then used to identify country of first birth in the Norwegian-born women. The age limit was chosen based on the fact that the youngest mothers in our dataset were 13 years of age.

\section{Adverse neonatal outcomes}

Gestational age was based on ultrasound estimation or, when such information was lacking, calculated from the first day of the last menstrual period. Very preterm birth, moderately preterm and post-term birth were defined as births in gestational week $22-31,32-36$ and $\geq 42$, respectively. In the analyses of very preterm birth, moderately preterm and post-term birth, we excluded births with unknown gestational age (migrant women $n=1512$; Norwegian-born women $n=12,677$ ) and term births were used as comparison group. In the analyses of small for gestational age (SGA) and large for gestational age (LGA) we also excluded births with unknown birthweight (migrant women $n=63$; Norwegian-born women $n=$ 403). For calculating SGA and LGA, we used Norwegian standards combining information on gestational age, birthweight and gender [20]. Low Apgar Score was defined as $<7$ at $5 \mathrm{~min}$. Stillbirth was defined as a pregnancy loss at $\geq 22$ weeks of gestation or birthweight $\geq 500 \mathrm{~g}$ if data on gestational age were missing. Neonatal death was defined as a live born infant at $\geq 22$ weeks of gestation (or with a birthweight $\geq 500 \mathrm{~g}$ if data on gestational age was missing) who died within 28 days after the birth.

\section{Other variables}

From the MBRN, we also obtained data on year of birth, maternal age $(<25,25-34, \geq 35$ years), single status (yes, no), parity $(1,2,3, \geq 4)$, smoking in early pregnancy (yes/ no) and previous stillbirth (yes, no).

For each birth year, SSB provided data on maternal level of education (no education, primary school, secondary school, university/college, missing), mother's gross income (categorized into quartiles, missing), reason for immigration (Nordic migrants, work/education, family reunion or establishment, refugee, missing), and paternal origin (Norwegian-born, foreign-born, missing). Maternal country of birth from SSB was used to classify women according to seven Global Burden of Disease super regions (GBD) [21]: High income countries; Central Europe, Eastern Europe, and Central Asia; Sub-Saharan Africa; North Africa and Middle East; South Asia; Southeast Asia, East Asia, and Oceania; Latin America and Caribbean. Maternal length of residence was calculated as the difference between the year of birth and the year a woman officially received her permission to stay in Norway $(<2$ years, $2-5$ years, $6-9$ years, $\geq 10$ years). Maternal age at immigration was calculated as the difference between maternal age at birth and her length of residence ( $<18$ years, $\geq 18$ years).

\section{Statistics}

Neonatal outcomes were compared between births to: 1 ) migrant women with a first birth before immigration to Norway versus those with a first birth after immigration, and 2) Norwegian-born women with a first birth outside 
Norway versus those with a first birth in Norway. We also compared births to migrant women with a first birth before immigration to Norway versus Norwegianborn women with a first birth outside Norway.

Logistic regression analyses were used to investigate possible associations between country of first childbirth (Norway/Other than Norway) and adverse neonatal outcomes in subsequent births. Associations were reported as odds ratios with $95 \%$ confidence intervals. Adjustment variables were year of birth, maternal age, parity, marital status, maternal education and mother's gross income. To account for dependency between births by the same mother, we used robust standard errors that allowed for within-mother clustering.

To avoid list-wise deletion and potential bias due to missing data in covariates in the adjusted regression models, we used a multiple imputation technique to replace missing values in covariates. Ten imputed datasets were created using the multivariate normal model [22]. Separate imputation models were created for each neonatal outcome and included the respective outcome (very preterm birth, moderately preterm birth, post-term birth, SGA, LGA, low Apgar score, stillbirth or neonatal death), as well as country of first childbirth and adjustment variables.

Analyses were performed using Stata IC version 16 (Stata Statistical Software, College Station, TX, USA) for Windows.

\section{Results}

Table 1 shows the background characteristics of the four groups at the time of the woman's second birth. Compared to migrant women with a first birth in Norway, migrant women with a first birth before immigration to Norway had more often missing data on education, lower or missing data on income. They also reported higher smoking prevalence in early pregnancy, a higher rate of previous stillbirth, they were more often from Central Europe, Eastern Europe \& Central Asia, shorter length of residence in Norway, higher age at migration, a foreign-born father to the baby, or missing information on paternal origin. Further, they were less likely to originate from High income countries or North Africa \& Middle East. Compared with Norwegian-born women with a first birth in Norway, Norwegian-born women with a first birth outside Norway were more likely to: be younger, be of single status, have lower levels of education, have higher income, smoke in early pregnancy, have experienced a previous stillbirth, report a foreignborn father to the baby, or have missing information on paternal origin.

The prevalence of adverse neonatal outcomes in second and subsequent births to migrant and Norwegian-born women in relation to country of first birth is shown in Fig. 2 .
The prevalence of most adverse outcomes was slightly higher in births to migrant women with a first birth before immigration to Norway compared to those with a first birth after immigration: very preterm birth $(1.0 \%$ vs $0.8 \% ; p<$ $0.001)$, moderately preterm birth $(4.4 \%$ vs $3.9 \% ; p<0.001)$, post-term birth ( $5.8 \%$ vs $4.6 \% ; p<0.001)$, SGA $(12.7 \%$ vs $11.9 \%$; $p<0.001)$, low Apgar score (2.7\% vs $2.2 \%$; $p<0.001$ ), and stillbirth $(0.5 \%$ vs $0.4 \% ; p<0.01)$. For the migrant women the prevalence of LGA (11.8\% vs $12.1 \%$; $p=0.178$ ) and neonatal death $(0.2 \%$ vs $0.2 \% ; p=0.988)$ was similar in both groups.

Compared to those with a first birth in Norway (Fig. 2), Norwegian-born women with a first birth outside Norway had higher prevalence of moderately preterm birth $(5.0 \%$ vs $3.6 \%$; $p<0.001)$, SGA $(10.2 \%$ vs $7.4 \%$; $p<$ $0.001)$, low Apgar score (3.0\% vs $1.8 \% ; p<0.001)$ and stillbirth $(0.5 \%$ vs $0.4 \% ; p<0.05)$, and lower prevalence of post-term birth $(4.7 \%$ vs $6.6 \% ; p<0.001)$ and LGA $(13.5 \%$ vs $19.0 \% ; p<0.001)$. For the Norwegian-born women, the prevalence of very preterm birth $(0.9 \%$ vs $0.7 \% ; p=0.141)$ neonatal death $(0.2 \%$ vs $0.2 \% ; p=0.472)$ was similar in both groups.

In second and subsequent births to migrant and Norwegian-born women the prevalence of SGA was higher, and LGA lower, if the father of the baby was foreign-born compared to births where the father was Norwegian-born (SGA: $13.3 \%$ vs $8.7 \% ; p<0.001$ and $8.5 \%$ vs $7.3 \%$; $p<0.001$; LGA: $10.8 \%$ vs $15.1 \% ; p<0.001$ and $16.5 \%$ vs $19.1 \% ; p<0.001$, respectively) (not shown).

The crude and adjusted associations between migrant women's country of first birth and adverse neonatal outcomes are shown in Table 2. After adjustments for year of birth, parity, maternal age, marital status, maternal education and income, analyses show that women who gave birth to their first baby before immigrating to Norway had increased odds of very preterm birth $(\mathrm{aOR}=$ 1.27; CI 1.09-1.48), moderately preterm birth $(\mathrm{aOR}=$ 1.10; CI 1.02-1.18), post-term birth $(\mathrm{aOR}=1.19$; CI 1.11-1.27), low Apgar score $(\mathrm{aOR}=1.27$; CI 1.16-1.39) and stillbirth $(\mathrm{aOR}=1.29$; CI 1.05-1.58) compared to foreign-born women who had their first baby after immigrating to Norway. The results were similar when women from high-income countries were excluded from the analyses (data not shown).

The crude and adjusted associations between Norwegian-born women's country of first birth and adverse neonatal outcomes are shown in Table 3. The adjusted analyses show increased odds of very preterm birth $(\mathrm{aOR}=1.32 ; 1.00-1.73), \quad$ moderately preterm birth $(\mathrm{aOR}=1.36$; CI 1.19-1.55), post-term birth $(\mathrm{aOR}=1.23$; CI 1.08-1.40), SGA (aOR $=1.43$; CI 1.31-1.57), low Apgar score $(\mathrm{aOR}=1.61$; CI 1.38-1.88) and stillbirth $(\mathrm{aOR}=1.69$; CI 1.18-2.42), and decreased odds for LGA $(\mathrm{aOR}=0.74 ; \mathrm{CI} 0.68-0.80)$ in Norwegian-born women 
Table 1 Background characteristics at the time point for 2nd birth; migrant $(n=68,392)$ and Norwegian-born women $(n=369,528)^{a}$

\begin{tabular}{|c|c|c|c|c|c|c|c|c|}
\hline \multirow[b]{4}{*}{ Total } & \multicolumn{4}{|c|}{ Migrant women's first birth } & \multicolumn{4}{|c|}{ Norwegian-born women's first birth } \\
\hline & \multicolumn{2}{|c|}{ Before immigration } & \multicolumn{2}{|c|}{ After immigration } & \multicolumn{2}{|c|}{ Outside Norway } & \multicolumn{2}{|c|}{ In Norway } \\
\hline & $\mathrm{n}$ & $\%$ & $n$ & $\%$ & $\mathrm{n}$ & $\%$ & $\mathrm{n}$ & $\%$ \\
\hline & 21,793 & 31.9 & 46,599 & 68.1 & 4602 & 1.2 & 364,926 & 98.8 \\
\hline \multicolumn{9}{|l|}{ Age (years) } \\
\hline$<25$ & 3027 & 13.9 & 6631 & 14.2 & 1419 & 30.8 & 46,724 & 12.8 \\
\hline $25-34$ & 14,535 & 66.7 & 31,949 & 68.6 & 2991 & 65.0 & 267,908 & 73.4 \\
\hline$\geq 35$ & 4231 & 19.4 & 8019 & 17.2 & 192 & 4.2 & 50,294 & 13.8 \\
\hline Single status ${ }^{b}$ & 1365 & 6.3 & 3073 & 6.6 & 442 & 9.6 & 16,899 & 4.6 \\
\hline \multicolumn{9}{|l|}{ Mother's education } \\
\hline No education & 367 & 2.7 & 653 & 1.8 & 0 & 0.0 & 3 & 0.0 \\
\hline Primary education & 3889 & 28.3 & 10,275 & 28.3 & 1112 & 24.2 & 58,473 & 16.0 \\
\hline Secondary school & 3518 & 25.6 & 9244 & 25.4 & 1451 & 31.6 & 135,373 & 37.1 \\
\hline University/college & 5985 & 43.5 & 16,188 & 44.5 & 2023 & 44.1 & 170,715 & 46.8 \\
\hline Mother's education, missing & 8034 & 36.9 & 10,239 & 22.0 & 16 & 0.4 & 362 & 0.1 \\
\hline \multicolumn{9}{|l|}{ Mother's income } \\
\hline$\leq 25$ percentile & 5194 & 41.9 & 9386 & 26.8 & 692 & 15.9 & 61,779 & 18.0 \\
\hline 25-50 percentile & 1971 & 15.9 & 5981 & 17.1 & 674 & 15.5 & 83,609 & 24.3 \\
\hline 50-75 percentile & 2784 & 22.4 & 8838 & 25.2 & 1143 & 26.3 & 98,455 & 28.6 \\
\hline$\geq 75$ percentile & 2455 & 19.8 & 10,839 & 30.9 & 1839 & 42.3 & 100,274 & 29.1 \\
\hline Mother's income, missing & 9389 & 43.1 & 11,555 & 24.8 & 254 & 5.5 & 20,809 & 5.7 \\
\hline Smoking in early pregnancy ${ }^{c}$ & 1203 & 7.8 & 1611 & 4.7 & 709 & 17.7 & 32,810 & 14.0 \\
\hline Previous stillbirth & 214 & 1.2 & 235 & 0.6 & 77 & 1.8 & 1075 & 0.4 \\
\hline
\end{tabular}

Migration

Maternal origin (GBD)

High income country

Central Europe, Eastern Europe \& Central Asia

Sub-Saharan Africa

North Africa \& Middle East

South Asia

Southeast Asia, East Asia

\& Oceania

Latin America \& Caribbean

Reason for immigration

$$
\text { Nordic migrants }
$$

Work/education

Family reunion/establishment

$$
\text { Refugee }
$$

Reason for immigration, missing

Length of Residence

\begin{tabular}{|c|c|c|c|}
\hline 3864 & 17.7 & 10,266 & 22.0 \\
\hline 7488 & 34.4 & 11,076 & 23.8 \\
\hline 2714 & 12.5 & 5491 & 11.8 \\
\hline 2482 & 11.4 & 7797 & 16.7 \\
\hline 873 & 4.0 & 3208 & 6.9 \\
\hline 3625 & 16.6 & 7516 & 16.1 \\
\hline 747 & 3.4 & 1245 & 2.7 \\
\hline 1720 & 8.0 & 5514 & 12.0 \\
\hline 3170 & 14.8 & 7960 & 17.3 \\
\hline 12,789 & 59.5 & 25,338 & 55.1 \\
\hline 3817 & 17.8 & 7137 & 15.5 \\
\hline 297 & 1.4 & 650 & 1.4 \\
\hline 10,659 & 48.9 & 1801 & 3.9 \\
\hline 8618 & 39.5 & 22,952 & 49.3 \\
\hline 1751 & 8.0 & 13,116 & 28.2 \\
\hline 765 & 3.5 & 8730 & 18.7 \\
\hline
\end{tabular}

$$
\begin{aligned}
& <2 \text { years } \\
& 2-5 \text { years } \\
& 6-9 \text { years } \\
& \geq 10 \text { years }
\end{aligned}
$$


Table 1 Background characteristics at the time point for 2 nd birth; migrant $(n=68,392)$ and Norwegian-born women $(n=369,528)^{a}$ (Continued)

\begin{tabular}{|c|c|c|c|c|c|c|c|c|}
\hline \multirow[b]{4}{*}{ Total } & \multicolumn{4}{|c|}{ Migrant women's first birth } & \multicolumn{4}{|c|}{ Norwegian-born women's first birth } \\
\hline & \multicolumn{2}{|c|}{ Before immigration } & \multicolumn{2}{|c|}{ After immigration } & \multicolumn{2}{|c|}{ Outside Norway } & \multicolumn{2}{|c|}{ In Norway } \\
\hline & $\mathrm{n}$ & $\%$ & $n$ & $\%$ & $\mathrm{n}$ & $\%$ & $n$ & $\%$ \\
\hline & 21,793 & 31.9 & 46,599 & 68.1 & 4602 & 1.2 & 364,926 & 98.8 \\
\hline Age at migration $<18$ years & 367 & 1.7 & 5231 & 11.2 & & & & \\
\hline Foreign-born father & 13,359 & 81.7 & 29,094 & 64.7 & 594 & 13.3 & 21,058 & 5.8 \\
\hline Paternal origin, missing & 5431 & 24.9 & 1636 & 3.5 & 148 & 3.2 & 3282 & 0.9 \\
\hline
\end{tabular}

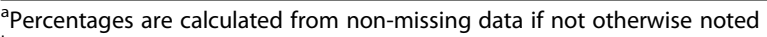

${ }^{b}$ Includes unmarried, single, divorced, separated, widowed and other/missing.

'Data on smoking from 1999 onwards

with a first birth outside Norway, compared to Norwegianborn women with a first birth in Norway.

Finally, we compared the outcomes for migrants and Norwegian-born women who all had had their first birth outside Norway. After adjustments for year of birth, parity, maternal age, marital status, maternal education and income, migrant women had increased odds for SGA (aOR = 1.18; CI 1.06-1.32), and decreased odds of moderately preterm birth $(\mathrm{aOR}=0.72$; CI $0.62-0.85)$, LGA $(\mathrm{aOR}=$ 0.84; CI 0.75-0.93) and low Apgar score $(\mathrm{aOR}=0.81$; CI 0.67-0.98), relative to Norwegian-born women with a first birth outside Norway.

\section{Discussion}

Migrant women with a first birth before immigration to Norway were more likely to experience adverse neonatal

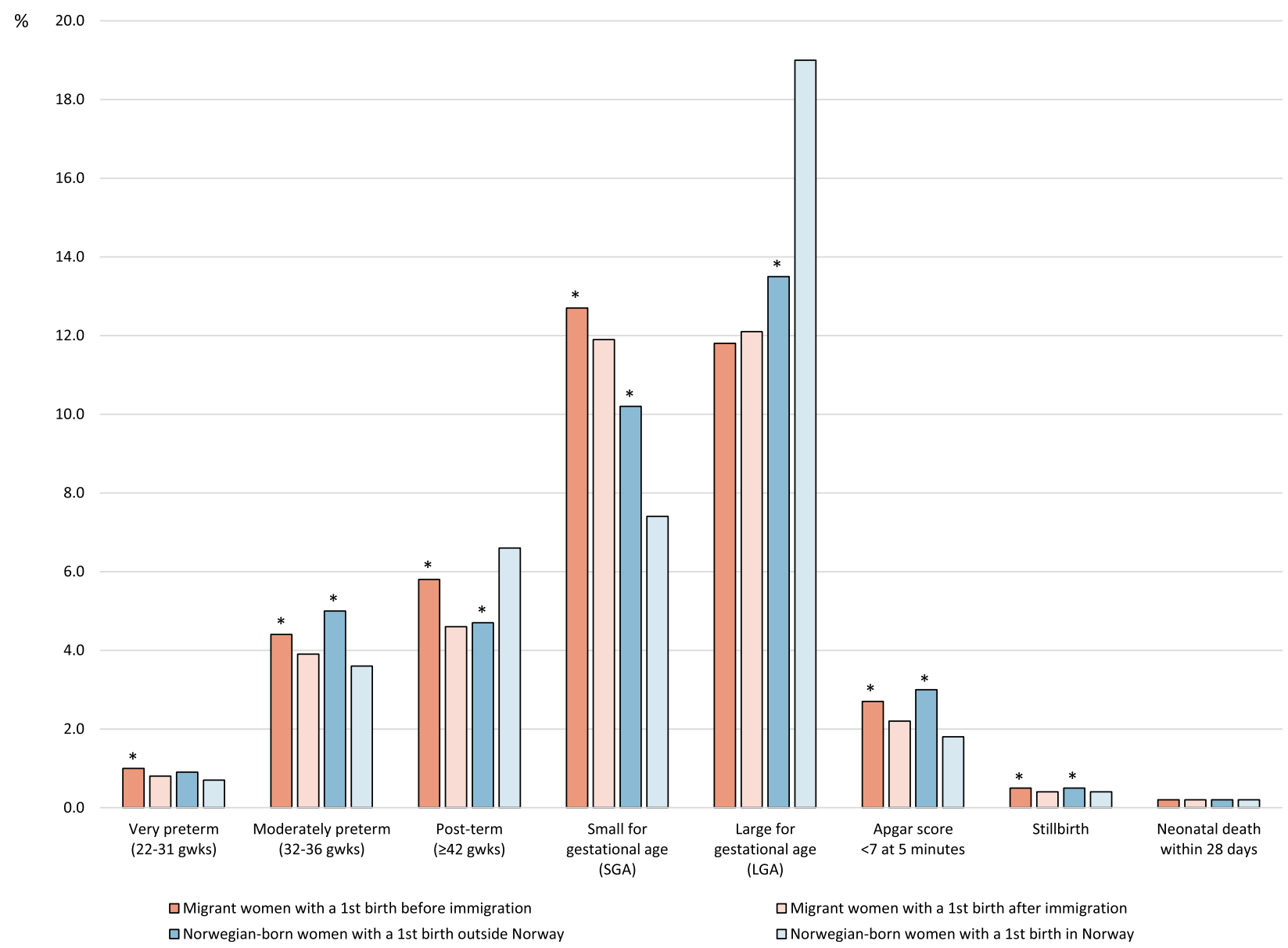

Fig. 2 Prevalence of adverse neonatal outcomes in second and subsequent births in migrant and Norwegian-born women (1990-2016). * $p$ values $<0.05$, when comparing birth outcomes in either the two groups of migrant women or the two groups of Norwegian-born women 
Table 2 Associations between migrant women's country of first birth and adverse neonatal outcomes (1990-2016)

\begin{tabular}{|c|c|c|c|c|c|c|}
\hline Adverse neonatal outcomes & $\mathrm{n}$ births & $\mathrm{n}$ cases & $\begin{array}{l}\text { Crude OR } \\
(95 \% \mathrm{Cl})\end{array}$ & $\begin{array}{l}\text { Adjusted OR } \\
(95 \% \mathrm{Cl})^{*}\end{array}$ & $\begin{array}{l}\text { Adjusted OR } \\
(95 \% \mathrm{Cl}) \dagger\end{array}$ & $\begin{array}{l}\text { Adjusted OR } \\
(95 \% \mathrm{Cl}) \neq\end{array}$ \\
\hline \multicolumn{7}{|l|}{$\begin{array}{l}\text { Very preterm } \\
(22-31 \text { weeks }) \S\end{array}$} \\
\hline Norway & 62,366 & 532 & 1.00 & 1.00 & 1.00 & 1.00 \\
\hline Other & 27,965 & 308 & $1.29(1.12-1.50)$ & $1.26(1.09-1.47)$ & $1.26(1.09-1.46)$ & $1.27(1.09-1.48)$ \\
\hline \multicolumn{7}{|l|}{$\begin{array}{l}\text { Moderately preterm } \\
(32-36 \text { weeks }) \S\end{array}$} \\
\hline Norway & 64,348 & 2514 & 1.00 & 1.00 & 1.00 & 1.00 \\
\hline Other & 28,938 & 1281 & $1.14(1.06-1.22)$ & $1.11(1.03-1.19)$ & $1.11(1.03-1.19)$ & $1.10(1.02-1.18)$ \\
\hline \multicolumn{7}{|l|}{ Post-term ( $\geq 42$ weeks)§ } \\
\hline Norway & 62,096 & 2994 & 1.00 & 1.00 & 1.00 & 1.00 \\
\hline Other & 27,825 & 1701 & $1.29(1.20-1.37)$ & $1.21(1.13-1.29)$ & $1.20(1.13-1.29)$ & $1.19(1.12-1.27)$ \\
\hline \multicolumn{7}{|l|}{$\begin{array}{l}\text { Small for gestational } \\
\text { age (SGA) }\end{array}$} \\
\hline Norway & 65,092 & 7738 & 1.00 & 1.00 & 1.00 & 1.00 \\
\hline Other & 29,401 & 3743 & $1.08(1.03-1.13)$ & $1.07(1.02-1.12)$ & $1.07(1.02-1.12)$ & $1.05(1.00-1.10)$ \\
\hline \multicolumn{7}{|l|}{$\begin{array}{l}\text { Large for gestational } \\
\text { age (LGA) }\end{array}$} \\
\hline Norway & 65,092 & 7847 & 1.00 & 1.00 & 1.00 & 1.00 \\
\hline Other & 29,401 & 3454 & $0.97(0.93-1.02)$ & $0.97(0.92-1.01)$ & $0.97(0.93-1.02)$ & $0.98(0.93-1.03)$ \\
\hline \multicolumn{7}{|l|}{ Apgar score $<7$ at $5 \mathrm{~min}$} \\
\hline Norway & 66,006 & 1418 & 1.00 & 1.00 & 1.00 & 1.00 \\
\hline Other & 30,062 & 824 & $1.28(1.18-1.40)$ & $1.28(1.17-1.40)$ & $1.27(1.16-1.39)$ & $1.27(1.16-1.39)$ \\
\hline \multicolumn{7}{|l|}{ Stillbirth } \\
\hline Norway & 66,006 & 261 & 1.00 & 1.00 & 1.00 & 1.00 \\
\hline Other & 30,062 & 157 & $1.32(1.08-1.62)$ & $1.29(1.06-1.58)$ & $1.29(1.05-1.59)$ & $1.29(1.05-1.58)$ \\
\hline \multicolumn{7}{|l|}{$\begin{array}{l}\text { Neonatal death } \\
\text { within } 28 \text { days }\end{array}$} \\
\hline Norway & 66,006 & 138 & 1.00 & 1.00 & 1.00 & 1.00 \\
\hline Other & 30,062 & 63 & $1.00(0.74-1.36)$ & $0.96(0.71-1.30)$ & $0.96(0.70-1.30)$ & $0.95(0.69-1.30)$ \\
\hline
\end{tabular}

* Adjusted for year of birth, parity, maternal age and marital status

$\uparrow$ Adjusted for * and maternal education

₹ Adjusted for * $\dagger$ and mother's gross income

$\S$ Weeks of gestation; term births were used as comparison group

outcomes in subsequent births in Norway when compared to migrant women with a first birth after immigration. Likewise, Norwegian-born women with a first birth outside Norway had increased risk for adverse neonatal outcomes in later births when compared to Norwegianborn women with a first birth in Norway.

To our knowledge, this is the first study to investigate a number of adverse neonatal outcomes in subsequent births after a first birth before immigrating to a new country. A first birth before immigration to Norway was associated with increased odds of very preterm, moderately preterm and post-term birth, low Apgar score and stillbirth. Even if the individual's risk for these adverse neonatal outcomes is small, the conditions are severe with consequences for the family [23] and high costs for society, such as neonatal intensive care and long-term complex health needs [24].

The higher odds of adverse outcomes in migrant women with a first birth before immigration may partly be attributed to the stress of migration. Maternal stress during pregnancy has been identified as an independent risk factor for preterm birth [25], also specific for refugee women [7]. Migrating with children may add to the stress of migration [26, 27], and some women may struggle with feelings of loss or regret after leaving older child(ren) behind [28-30]. Further, near half the women who had given birth before immigration had been in Norway for less than 2 years when their second child was born. These women may lack familiarity with the health care system [31, 32], struggle with language 
Table 3 Associations between Norwegian-born women's country of first birth and adverse neonatal outcomes (1990-2016)

\begin{tabular}{|c|c|c|c|c|c|c|}
\hline Adverse neonatal outcomes & $\mathrm{n}$ births & $\mathrm{n}$ cases & $\begin{array}{l}\text { Crude OR } \\
(95 \% \text { Cl) }\end{array}$ & $\begin{array}{l}\text { Adjusted OR } \\
(95 \% \mathrm{Cl})^{*}\end{array}$ & $\begin{array}{l}\text { Adjusted OR } \\
(95 \% \mathrm{Cl}) \dagger\end{array}$ & $\begin{array}{l}\text { Adjusted OR } \\
(95 \% \mathrm{Cl}) \neq\end{array}$ \\
\hline \multicolumn{7}{|l|}{ Very preterm (22-31 weeks)§ } \\
\hline Norway & 480,589 & 3592 & 1.00 & 1.00 & 1.00 & 1.00 \\
\hline Other & 5865 & 54 & $1.23(0.94-1.62)$ & $1.32(1.01-1.74)$ & $1.31(1.00-1.72)$ & $1.32(1.00-1.73)$ \\
\hline \multicolumn{7}{|l|}{$\begin{array}{l}\text { Moderately preterm } \\
(32-36 \text { weeks)§ }\end{array}$} \\
\hline Norway & 495,060 & 18,063 & 1.00 & 1.00 & 1.00 & 1.00 \\
\hline Other & 6117 & 306 & $1.39(1.22-1.58)$ & $1.37(1.20-1.57)$ & $1.36(1.19-1.55)$ & $1.36(1.19-1.55)$ \\
\hline \multicolumn{7}{|l|}{ Post-term ( $\geq 42$ weeks)§ } \\
\hline Norway & 480,497 & 33,033 & 1.00 & 1.00 & 1.00 & 1.00 \\
\hline Other & 5815 & 291 & $0.71(0.63-0.81)$ & $1.23(1.08-1.40)$ & $1.23(1.08-1.40)$ & $1.23(1.08-1.40)$ \\
\hline \multicolumn{7}{|l|}{$\begin{array}{l}\text { Small for gestational } \\
\text { age (SGA) }\end{array}$} \\
\hline Norway & 501,753 & 37,174 & 1.00 & 1.00 & 1.00 & 1.00 \\
\hline Other & 6171 & 632 & $1.43(1.30-1.56)$ & $1.45(1.33-1.59)$ & $1.44(1.31-1.57)$ & $1.43(1.31-1.57)$ \\
\hline \multicolumn{7}{|l|}{$\begin{array}{l}\text { Large for gestational } \\
\text { age (LGA) }\end{array}$} \\
\hline Norway & 501,753 & 95,058 & 1.00 & 1.00 & 1.00 & 1.00 \\
\hline Other & 6171 & 834 & $0.67(0.62-0.73)$ & $0.73(0.67-0.80)$ & $0.74(0.68-0.80)$ & $0.74(0.68-0.80)$ \\
\hline \multicolumn{7}{|l|}{$\begin{array}{l}\text { Apgar score }<7 \\
\text { at } 5 \mathrm{~min}\end{array}$} \\
\hline Norway & 514,799 & 9279 & 1.00 & 1.00 & 1.00 & 1.00 \\
\hline Other & 6205 & 187 & $1.69(1.46-1.97)$ & $1.62(1.39-1.89)$ & 1.61 (1.39-1.88) & $1.61(1.38-1.88)$ \\
\hline \multicolumn{7}{|l|}{ Stillbirth } \\
\hline Norway & 514,799 & 1789 & 1.00 & 1.00 & 1.00 & 1.00 \\
\hline Other & 6205 & 31 & $1.44(1.01-2.05)$ & $1.69(1.18-2.42)$ & $1.67(1.17-2.40)$ & $1.69(1.18-2.42)$ \\
\hline \multicolumn{7}{|l|}{$\begin{array}{l}\text { Neonatal death } \\
\text { within } 28 \text { days }\end{array}$} \\
\hline Norway & 514,799 & 808 & 1.00 & 1.00 & 1.00 & 1.00 \\
\hline Other & 6205 & 12 & $1.23(0.70-2.18)$ & 1.59 (0.89-2.83) & $1.58(0.89-2.81)$ & $1.59(0.89-2.83)$ \\
\hline
\end{tabular}

* Adjusted for year of birth, parity, maternal age and marital status

† Adjusted for ${ }^{*}$ and maternal education

₹ Adjusted for *, $\uparrow$ and mother's gross income

$\S$ Weeks of gestation; term births were used as comparison group

barriers [31] or make suboptimal use of the services [33-35]. Some migrant women also delay their first antenatal visit [34-36], making it difficult to collect a thorough obstetric history. Migrant women are also a heterogeneous group arriving from different countries for a variety of reasons and with different socioeconomic and cultural backgrounds, thus the findings in this study may not apply to all migrant women with a first birth before immigration. Recognizing the complexity of migration is crucial when addressing the various needs of migrant women in maternity care [37].

Somewhat surprisingly, the results related to Norwegian-born women were similar to the ones in the migrant population. A lack of access to information about obstetric history may therefore explain some of the negative outcomes in women with a first birth before immigration. Less attention is often given to parous compared to nulliparous women in antenatal care [10], and health care providers may have less access to previous medical records [31]. Hence, the needs of both migrant and Norwegian-born parous women returning after a first birth abroad may currently be inadequately addressed. Interpretation of the differences between migrant and Norwegian-born women must be made cautiously however, as although we know that migrant women immigrated for a range of reasons, including fleeing war and conflict, we lacked information on the reasons for spending time abroad in the Norwegianborn sample. An alternative explanation for the increased risk of adverse outcomes in the Norwegian-born 
sample may be that Norwegian-born women who had experienced adverse birth outcomes abroad returned home before their next birth. In our sample, having experienced a previous stillbirth was more common in the Norwegian-born sample of women with a first birth outside Norway compared to Norwegian-born women who had not given birth abroad.

Both migrant and Norwegian-born women with a first birth outside Norway were more likely to report a foreignborn father to the baby compared to women who gave birth to their first child in Norway, and a foreign-born father was associated with an increased prevalence of SGA and a decreased prevalence of LGA in our material. The differences in birthweight between migrant and nonmigrant women are difficult to interpret $[38,39]$. Such differences may be attributed to normal biological variation as paternal factors can influence fetal growth [40, 41]. However, differences may also reflect maternal and infant health problems or suboptimal care, as infants may be growth-restricted for a variety of reasons [41]. A critical review on birthweight in immigrant populations concludes that birthweight alone is not enough to inform clinical decisions and newborn size charts should serve as screening rather than diagnostic tools [38]. The associations between a foreign-born father and adverse neonatal outcomes need further investigation.

The main strengths of this study include the large sample size and long timespan of the study allowing us to follow the same mothers and their pregnancy outcomes over time ( 26 years). The standardized collection of data on adverse neonatal outcomes, and the selection of available covariates adjusted for in the regression analyses, add to the strengths of the study. The differences in background characteristics in the Norwegianborn sample are mainly a result of the age limit set to determine country of first birth in these women, and this may limit the conclusions that can be drawn from the Norwegian-born sample. Additionally, we cannot rule out misclassification of self-reported parity. Finally, the low prevalence of adverse outcomes in both migrant and Norwegian-born women limited us from determining if the increased risk of adverse neonatal outcomes was primarily related to the first birth after arriving in Norway or if it also applied to later births to the same mother.

\section{Conclusions}

Both migrant and Norwegian-born women had increased odds of adverse neonatal outcomes in subsequent births if they had their first baby outside Norway compared with if they had their first baby in Norway. The results of this study should serve as a reminder of the importance of collecting a thorough obstetric history from parous women who migrate to a new country after their first birth.

\section{Abbreviations}

aOR: Adjusted odds ratio; Cl: Confidence interval; MBRN: Medical Birth Registry of Norway; OR: Odds ratio; SSB: Statistics Norway

\section{Acknowledgements}

We thank the Medical Birth Registry of Norway (MBRN) and Statistics Norway for providing data for this study.

\section{Authors' contributions}

ESV, ES, RMN and VA planned the study, drafted the first version of the manuscript and contributed to data management, statistical analysis and interpretation of data; RS and DM made their contribution in revising the manuscript. The final manuscript was read and approved by all authors.

\section{Funding}

Faculty of Health and Social Sciences (Western Norway University of Applied Sciences, Norway) was the main funder of this study. Working hours for ES were funded by the Centre for Clinical Research Dalarna (Uppsala University, Sweden). Additional data costs were funded by the Norwegian SIDS and Stillbirth Society.

\section{Availability of data and materials}

The data that support the findings of this study are available from the Medical Birth Registry of Norway and Statistics Norway but restrictions apply to the availability of these data, which were used under license for the current study, and so are not publicly available. Data are however available from the authors upon reasonable request and with permission of the Medical Birth Registry of Norway and Statistics Norway.

Ethics approval and consent to participate

The study was approved by the South-East Regional Committees for Medical and Health Research Ethics in Norway (approval number: 2014/1278). Data were used under licence for the current study.

\section{Consent for publication}

Not applicable.

\section{Competing interests}

The authors declare that they have no competing interests.

\section{Author details}

${ }^{1}$ Faculty of Health and Social Sciences, Western Norway University of Applied Sciences, Campus Kronstad, Inndalsveien 28, 5063 Bergen, Norway. ${ }^{2}$ Department of Global Public Health and Primary Care, University of Bergen, Bergen, Norway. ${ }^{3}$ Department of Women's and Children's Health, Karolinska Institutet, Stockholm, Sweden. ${ }^{4} J u d i t h$ Lumley Centre, La Trobe University, Melbourne, Australia. ${ }^{5}$ Department of Pediatrics, Haukeland University Hospital, Bergen, Norway. ${ }^{6}$ Centre for Clinical Research Dalarna, Uppsala University, Uppsala, Sweden.

Received: 15 November 2019 Accepted: 9 June 2020

Published online: 15 June 2020

\section{References}

1. World Health Organization. Report on the health of refugees and migrants in the WHO European Region. 2018.

2. Bevelander PH, Bilde R, Dahlstedt I, Eskelund M, Møller Hansen L, Macura M, et al. Scandinavia's population groups originating from developing countries: change and integration. Nordic Council of Ministers: Copenhagen; 2013.

3. Gagnon AJ, Zimbeck M, Zeitlin J, Collaboration R. Migration to western industrialised countries and perinatal health: a systematic review. Soc Sci Med. 2009;69(6):934-46.

4. Urquia ML, O'Campo PJ, Heaman MI. Revisiting the immigrant paradox in reproductive health: the roles of duration of residence and ethnicity. Soc Sci Med. 2012;74(10):1610-21.

5. Urquia ML, Gagnon AJ. Glossary: migration and health. J Epidemiol Community Health. 2011;65(5):467-72.

6. Wanigaratne S, Cole DC, Bassil K, Hyman I, Moineddin R, Urquia ML. The influence of refugee status and secondary migration on preterm birth. J Epidemiol Community Health. 2016;70(6):622-8. 
7. Liu C, Urquia M, Cnattingius S, Hjern A. Migration and preterm birth in war refugees: a Swedish cohort study. Eur J Epidemiol. 2014;29(2):141-3.

8. Gissler M, Alexander S, MacFarlane A, Small R, Stray-Pedersen B, Zeitlin J, et al. Stillbirths and infant deaths among migrants in industrialized countries. Acta Obstet Gynecol Scand. 2009;88(2):134-48.

9. The World Bank. Fertility rate, total (births per woman) 2017 [Available from: https://data.worldbank.org/indicator/sp.dyn.tfrt.in.

10. The National Institute for Health and Care Excellence. Antenatal care for uncomplicated pregnancies 2008 [Available from: https://www.nice.org.uk/ guidance/CG62.

11. Vik ES, Aasheim V, Schytt E, Small R, Moster D, Nilsen RM. Stillbirth in relation to maternal country of birth and other migration related factors: a population-based study in Norway. BMC Pregnancy Childbirth. 2019;19(1):5.

12. Medical Birth Registry of Norway. Medical Birth Registry of Norway 2016 [Available from: https://www.fhi.no/en/hn/health-registries/medical-birthregistry-of-norway/medical-birth-registry-of-norway/.

13. Irgens LM. The Medical Birth Registry of Norway. Epidemiological research and surveillance throughout 30 years. Acta Obstet Gynecol Scand. 2000;79:435-9.

14. Statistics Norway. About Statistics Norway 2019 [Available from: http://www. ssb.no/en/omssb/om-oss.

15. World Health Organization. World Health Statistics 2018: Monitoring health for the SDGs 2018.

16. Norwegian Directorate of Health. Pregnancy and maternity care in Norway 2017 [Available from: https://helsenorge.no/other-languages/english/ pregnancy-and-maternity-care.

17. The Norwegian Directorate of Health. Et trygt fødetilbud : kvalitetskrav for fødeinstitusjoner. Oslo: Helsedirektoratet; 2010.

18. Saastad E, Vangen S, Frøen JF. Suboptimal care in stillbirths-a retrospective audit study. Acta Obstet Gynecol Scand. 2007;86(4):444-50.

19. Statistics Norway. Total fertility rate and number of live births, by mother's country background, contents and year 2019 [Available from: https://www. ssb.no/en/statbank/table/12481/tableViewLayout1/.

20. Skjaerven R, Gjessing HK, Bakketeig LS. Birthweight by gestational age in Norway. Acta Obstet Gynecol Scand. 2000;79:440-9.

21. Institute for Health Metrics and Evaluation. GBD Compare: University of Washington; 2017 [Available from: https://vizhub.healthdata.org/gbdcompare/.

22. StataCorp. Stata Multiple-Imputation Reference Manual Release 152017. Available from: https://www.stata.com/bookstore/multiple-imputationreference-manual/

23. Heazell AEP, Siassakos D, Blencowe H, Burden C, Bhutta ZA, Cacciatore J, et al. Stillbirths: economic and psychosocial consequences. Lancet. 2016; 387(10018):604-16.

24. Blencowe H, Cousens S, Chou D, Oestergaard M, Say L, Moller A-B, et al. Born too soon: the global epidemiology of 15 million preterm births. Reprod Health. 2013;10(1):S2.

25. Lilliecreutz C, Larén J, Sydsjö G, Josefsson A. Effect of maternal stress during pregnancy on the risk for preterm birth. BMC Pregnancy Childbirth. 2016;16(1):5.

26. Schweitzer RD, Vromans L, Brough M, Asic-Kobe M, Correa-Velez I, Murray K, et al. Recently resettled refugee women-at-risk in Australia evidence high levels of psychiatric symptoms: individual, trauma and post-migration factors predict outcomes. BMC Med. 2018;16(1):149.

27. Miranda J, Siddique J, Der-Martirosian C, Belin TR. Depression among Latina immigrant mothers separated from their children. Psychiatr Serv. 2005;56(6): $717-20$

28. Goodman RD, Vesely CK, Letiecq B, Cleaveland CL. Trauma and resilience among refugee and undocumented immigrant women. J Counseling Dev. 2017:95(3):309-21.

29. Sternberg RM, Barry C. Transnational mothers crossing the border and bringing their health care needs. J Nurs Scholarsh. 2011;43(1):64-71.

30. Straiton ML, Ledesma HML, Donnelly $\Pi T$. A qualitative study of Filipina immigrants' stress, distress and coping: the impact of their multiple, transnational roles as women. BMC Womens Health. 2017;17(1):72.

31. Priebe S, Sandhu S, Dias S, Gaddini A, Greacen T, loannidis E, et al. Good practice in health care for migrants: views and experiences of care professionals in 16 European countries. BMC Public Health. 2011;11(1):187.

32. Straiton ML, Myhre $\mathrm{S}$. Learning to navigate the healthcare system in a new country: a qualitative study. Scand J Prim Health Care. 2017;35(4):352-9.

33. Unterscheider J, Ma'ayeh M, Geary MP. Born before arrival births: impact of a changing obstetric population. J Obstet Gynaecol. 2011;31(8):721-3.
34. Råssjö EB, Byrskog U, Samir R, Klingberg-Allvin M. Somali women's use of maternity health services and the outcome of their pregnancies: a descriptive study comparing Somali immigrants with native-born Swedish women. Sexual Reprod Healthcare. 2013;4(3):99-106.

35. Alderliesten ME, Stronks K, van Lith JM, Smit BJ, van der Wal MF, Bonsel GJ, et al. Ethnic differences in perinatal mortality: a perinatal audit on the role of substandard care. Eur J Obstet Gynecol Reprod Biol. 2008;138(2):164-70.

36. Alderliesten ME, Vrijkotte TG, van der Wal MF, Bonsel GJ. Late start of antenatal care among ethnic minorities in a large cohort of pregnant women. Bjog. 2007;114(10):1232-9.

37. Essén B, Puthoopparambil SJ, Mosselmans L, Salzmann T. Improving the health care of pregnant refugee and migrant women and newborn children: technical guidance. WHO Regional Office for Europe; 2018.

38. Urquia ML, Sørbye IK, Wanigaratne S. Birth-weight charts and immigrant populations: a critical review. Best Practice Res Clin Obstet Gynaecol. 2016; 32:69-76.

39. Urquia ML, Berger H, Ray JG. Risk of adverse outcomes among infants of immigrant women according to birth-weight curves tailored to maternal world region of origin. CMAJ. 2015;187(1):E32-40.

40. Jaquet D, Swaminathan S, Alexander GR, Czernichow P, Collin D, Salihu HM, et al. Significant paternal contribution to the risk of small for gestational age. BJOG Int J Obstet Gynaecol. 2005;112(2):153-9.

41. McCowan L, Horgan RP. Risk factors for small for gestational age infants. Best Practice Res Clin Obstet Gynaecol. 2009;23(6):779-93.

\section{Publisher's Note}

Springer Nature remains neutral with regard to jurisdictional claims in published maps and institutional affiliations.
Ready to submit your research? Choose BMC and benefit from:

- fast, convenient online submission

- thorough peer review by experienced researchers in your field

- rapid publication on acceptance

- support for research data, including large and complex data types

- gold Open Access which fosters wider collaboration and increased citations

- maximum visibility for your research: over $100 \mathrm{M}$ website views per year

At BMC, research is always in progress.

Learn more biomedcentral.com/submissions 